\section{Technical and Scale Efficiency in Nursery Enterprises in an Area of Significant Widespread Horticulture in Italy}

\author{
Giuseppe Timpanaro', Arturo Urso, and Vera T. Foti \\ Dipartimento di Agricoltura, Alimentazione e Ambiente (Di3A), University of \\ Catania, Via S. Sofia, 98/100, Catania 95123, Italy
}

Additional index words. data envelopment analysis (DEA), technical and economic efficiency, Tobit regression model, scale of production, horticultural greenhouses

\begin{abstract}
The aim of this work is to identify the factors that influence the level of efficiency in horticultural nurseries and to estimate their impact on productivity as well as the direction and intensity with which they act. The investigation was focused on table tomatoes (Solanum lycopersicum L.), a species widely cultivated in horticultural greenhouses and in the open field, for which the recourse to transplantation represents a normal operation to the point that nurseries activate a large number of productive cycles for this species throughout the year with the aim of obtaining "ungrafted seedlings" or ready-to-use "grafted seedlings". This study used the methodological approach of data envelopment analysis (DEA) and Tobit regression and was able to identify which of the factors linked to management choices, professionalism, and the motivation of entrepreneurs have a notable influence on the level of efficiency reached by nurseries and which of these factors offer possibilities for increasing their levels of production. The results of this investigation reveal that in the nurseries, the possibilities for achieving increasing economies of scale are limited by the structural relationships between capital and land and between land and labor, by the production strategies in place, and by the degree of utilization of materials and labor.
\end{abstract}

Nursery activities hold a significant importance in the construction of the value chain of the horticultural sector (Source: European Nursery Stock Association-ENA on European nursery stock sector available on www.enaplants.eu; European Horticulture Network-EHN and U.S. Department of Agriculture National Agricultural Statistics Service, 2012 Census of Agriculture). Their importance is increasing for a country such as

Received for publication 15 Aug. 2017. Accepted for publication 15 Dec. 2017.

This study was carried out with the financial support of the Assessorato Risorse Agricole e Alimentari, Regione Sicilia "Progetto Sementiero Regionale-Analisi economiche" (Giuseppe Timpanaro, scientific coordinator) and FIR 2014 on "L'innesto erbaceo del pomodoro: qualità e sostenibilità delle produzioni" (Francesco Giuffrida, scientific coordinator).

The study is the result of full collaboration and therefore all authors accept full responsibility for it. The actual writing of sections "Introduction," "Analysis of the cause factors of inefficiency in the nurseries," and "Concluding considerations" is attributable to Giuseppe Timpanaro; the section "Conceptual framework" and "Economic results and production costs" is attributable to Arturo Urso; and the section "Materials and Methods," "Characteristics of the nurseries investigated," and "Results of the analysis of efficiency with the DEA method" is attributable to Vera Teresa Foti.

${ }^{1}$ Corresponding author. E-mail: giuseppe.timpanaro@ unict.it.
Italy, in which horticulture both in the open field and under shelter contributes significantly to the creation of income and employment and the socioeconomic sustainability of entire territories. The favorable performance of this sector, along with studies in the scientific literature related to technicaleconomic and market matters, suggests that there is an opportunity to expand the use of transplantation techniques even more widely as an alternative to sowing directly in the field to achieve advantages of a technical, environmental, and commercial nature (Power et al., 1991; Timpanaro et al., 2015). Modern nurseries have therefore become complex and articulated structures, marked by intensive cultivation systems with considerable utilization of fixed and circulating capital and ways of managing production processes. These systems have allowed an elevated degree of integration and coordination, along with market relationships, for the supply of raw materials and the placement of finished products that are no longer circumscribed at the territorial level but are directed toward interregional or national dimensions.

This organizational complexity is linked to the multiplicity of production cycles realized (in all of the cases, the sowing is done directly in multiholed containers inside greenhouses to control the entire process and guarantee the result from qualitativequantitative and phytosanitary points of view) and to the simultaneous presence of many sectors within the nursery structure that are able to assure a determined phase of the "seedling multiplication" productive process (collections of mother plants, seed beds, greenhouse cultivation, etc.) with the parceling of the enterprise's surface area, which renders the management of this business activity and the reaching of adequate levels of profitability somewhat difficult (Kubota et al., 2017; Rivard et al., 2010). This also occurs because, technically, the nurseries are multiproduct enterprises (many species and varieties and many cultivation cycles on the same unit of surface area within the same greenhouse in the same year), characterized by returns to scale that oscillate between constants, increasing and decreasing, in different production systems. Thus, only a limited number of enterprises manage to realize productive volumes capable of generating economies of scale and, therefore, of increasing net profits.

The contribution of this work lies, essentially, in exploring these aspects of nursery management and assessing to what extent the economic results of these activities could be attributable to differences in the efficiency of the nursery. The results are provided through the DEA method, a nonparametric method of analysis that is particularly versatile for the study of the efficiency of productive units and that is widely used for analyzing multiple input/output processes and for determining a score of relative efficiency between different enterprises/productive processes. The objective, therefore, is to evaluate the relative efficiency of each nursery in terms of radial distance from the efficient frontier, defined by best practices, and to identify the variations in the factors necessary so that an inefficient nursery emulates the benchmark (the group of nurseries of reference on the frontier). Finally, on the basis of a multivariate Tobit-type analysis, an estimation of the influence of a series of key variables preselected from among the technical-economic, structural, and managerial factors that are most relevant on the efficiency indicator is made.

\section{Conceptual Framework}

The DEA technique was originally defined by Charnes et al. (1978) with the intention of developing Farrell's measure of efficiency and making it operative in the field of linear programming.

Starting from the research of Farrell (1957), a conceptual framework was developed for the analysis of an enterprise's performance in terms of economic, technical, and allocative efficiency. The largest advantage of this type of analysis lies in the fact that it allows a global approach to the enterprise, simultaneously considering all the inputs and outputs (Coelli, 1995) rather than considering them in terms of yield, e.g., per unit of input entered.

From its original inception, DEA has rapidly spread to a multitude of fields of application and business sectors, from the public to the private, and has fueled a broad 
debate on goodness and limits of application. Liu et al. (2013) published an article in which they use the Web of Science database 19782010 and present the results of research on the applications made possible by DEA thus far.

With reference to the agri-food sector, it is possible to find vast literature on the use of DEA to determine the competitiveness, productivity, and efficiency of the sector and on the use of alternative tools. Certain useful comparative contributions are based on the parametric analysis of the stochastic and nonparametric (DEA) frontier in an attempt to combine the virtues of both approaches into a unitary framework that is applicable to retail and wholesale distribution (Kuosmanen, 2006). Among other contributions, we highlight that of Bonfiglio (2006), who measured the results of Italian agro-food cooperatives [also using a Tobit regression analysis for identifying differences in technical efficiency (TE)], and that of Aramyan et al. (2006), who analyzed various performance indicators of the agri-food supply chain. In regard to the role of cooperation, the work of Fanfani and Maccarini (2009) demonstrated the imbalance between the size of a cooperative and the levels of production achieved through DEA. Latruffe (2010), moreover, suggested a revision of the literature to redefine the concepts of productivity and performance and to illustrate the methods of measurement and the possible obtainable results. Dadura and Lee (2011) used DEA to determine the key factors of innovation in Taiwan's food industry and to define appropriate strategies for improving innovative capacity, taking into account the size of the enterprise. Mutonyi and Gyau (2014) proposed a conceptual model of measurement of marketing performance based on five constructs: efficacy, efficiency, adaptability, the quality of food products, and customer satisfaction, in light of the increased opportunities of the market created by globalization and the growing demand for traceability, food safety, and standards of quality. Pagotto and Halog (2016), moreover, proposed the principles of the circular economy for increasing the performance of environmental sustainability in the agri-food industry with economic and environmental measures. Finally, Folinas et al. (2015) shifted their attention to the logistical processes of the agri-food sector, proposing DEA as a means to determine the criticalities for the customer, the costs, and the contribution of logistics to the added value of services and products.

Furthermore, there are numerous applications of DEA to specific productive sectors. Among many such studies, we recall the contribution of Fare et al. (1985), who focused on the application of the production possibility frontier concept with a study on the efficiency of the primary sector in the Philippines, whereas Sharma et al. (1997, 1999) made use of DEA and the stochastic production frontier for the measurement of the productive efficiency of pig rearing in Hawaii. There are also several works regarding viticulture, such as those relating to quality wine in Spain (Aparicio et al., 2013) and to wine in Italy (Urso, 2014; Urso et al., 2015), that analyze changes in the level of efficiency of Italian wineries after the reform of the Wine COM (Common Organization of Agricultural Markets) through the use of the Farm Accountancy Data Network (FADN)RICA database. Similar studies have also been conducted in China (Liu and Lv, 2010) and in Spain (Martínez-Carrión et al., 2010), as well as in relation to a comparison of winemaking in Italy and Spain (SellersRubio et al., 2016). Other contributions can be found in the literature relating to fisheries in Greece (Voulgaris and Lemonakis, 2013) and to rice-wheat farming that aimed to identify the determinants of technical inefficiency inherent in the farming system in Pakistan (Javed et al., 2010). Another study investigated the dairy sector in Poland (Jarzębowski and Bezat-Jarzębowska, 2014) and dairy enterprises operating under both conventional and organic management systems in Finland (Sipiläinen and Oude Lansink, 2005) and in Australia (Fraser and Graham, 2005). An analysis of efficiency regarding citrus-growing enterprises in Italy (Madau, 2015) was carried out and both DEA and stochastic frontier analysis were used, and another study analyzed quality bean production in Greece (Karagiannis and Melfou, 2015).

\section{Materials and Methods}

The necessity of comparing productive units that are potentially very different has led to a narrowing of the range both of the factors of production and of the types of products that are offered. Among the various species offered in commercial assortments of nurseries, the tomato (Solanum lycopersicum L.) is always present because it is a species widely requested by horticulturists for growing in greenhouses and in open fields. Therefore, considering its diffusion, this species was chosen for comparison between different nurseries. The choice is consistent with the general rule that the ideal selection includes the minimum number of inputs and outputs necessary for adequately capturing all the essential aspects of the operations carried out by the enterprises that are subject to the study. Tomato is still the most common vegetable species in the area, with production of more than 422,000 tons and worth 287.5 million euros, equivalent to $30 \%$ of the regional production [Italian National Institute of Statistics (ISTAT) data]. Regarding the selection of the sample of nurseries to subject to direct survey, we used the data provided by the Agricultural General Census (ISTAT) and the public office for technical assistance in agriculture. Taking into account the objectives of the research, we focused our attention on Sicily to ensure a high degree of homogeneity of the sample in terms of the horticultural specialization and pedoclimatic characteristics of the territory, as well as of the structural and infrastructural characteristics of the sector. For sample selection and assurance of its correct representability, probabilistic sampling was performed with a stratified procedure. The criteria were the territorial location and the physical amplitude class, fixing an error rate of 0.01 . The extracted sample is equal to $22 \%$ of the universe. Among the inputs, we considered "materials" and related expenses (seed, containers, peat/soil, fertilizers/pesticides, polyethylene mulch/cover, etc.), "works and services" and related remuneration (operations in sowing and germination room, transfer to greenhouse, fertilizing/pesticide treatment, etc.), and "stocks and other attributions" and related reintegrations (taxes and contributions, interest on stock capital, salaries, land capital, stocks, maintenance costs, insurance, etc.). On the basis of the business accounting data, it was possible to detect the amount of fixed and circulating capital invested on each fund (land capital and stock capital). The structure of the production costs chosen is in line with the European Union (EU) standard defined for the calculation of the profitability of the sector or the FADN, a tool for assessing the income of farms and the impacts of the Common Agricultural Policy (European Commission, 2010). The reference year of the survey is 2016 and the choice of the period for study was dictated, above all, by the availability of accounting data. Both the dependent variables and predictive variables were considered in terms of value rather than quantity. This was necessary to extrapolate quantities of input and output referred to different products within productive structures with intensive sorting and repeated cultivation cycles and to solve the problem of the distribution of fixed factors between different crops (Basile et al., 2002). The use of variables expressed in terms of value leads to the incorporation of not only the input/ output ratio that determines TE but also the so-called allocative efficiency that is derived from the prices of the purchase of the factors and of the sale of the products into the estimate of business efficiency (Battese, 1992).

Using an ad hoc questionnaire form and face-to-face interviews, 70 nurseries located throughout Sicily were recorded and assisted by reference to the financial accounts of the enterprises concerned. Our elaborations were then carried out on 50 enterprises because incomplete questionnaires were discarded.

The evaluation of TE has been developed in several phases. It should be remembered that there are basically two classic models of DEA: the CRS (constant return scale) model, also known as CCR (Charnes, Cooper, and Rhodes, 1978), and the VRS (variable return scale) or BCC (Banker, Charnes, and Cooper, 1984) model. The first model assumes constant returns to scale, whereas the second, instead, analyses returns to scale variables and does not assume the proportionality between inputs and outputs.

Preliminarily, by adopting a model with constant scale returns, the nurseries that effectively use the resources at their disposal were identified. This type of analysis assumes 
two different perspectives, mirroring each other, given the hypothesis of constant returns: 1) it enabled us to identify as "efficient" those nurseries that, compared with others, manage to achieve a greater number of tomato seedlings, although using the same quantity of factors of production (orientation toward output), or 2) it enabled the identification of those nurseries that to produce the same number of seedlings, manage to use a lower quantity of productive resources (orientation toward inputs).

The final result of this type of analysis, as is well-known, is represented by the calculation of efficiency indicators, or an efficiency score, which is a radial measurement of the distance of each nursery from those which, with the same combination of factors, manage to achieve better results or, alternatively, the same result with a lower use of resources.

The next step consisted of an evaluation, for each efficient nursery, of how many productive units are ineffectively used within its structure. In this way, from among the most efficient nurseries, those that were most representative in terms of the optimal organization of resources were identified.

The DEA then, as is well-known, allows the decomposition of the overall inefficiency into genuine technical inefficiency or, in other words, into the incapacity of an enterprise to optimally combine the factors of production and to obtain the highest possible number of tomato seedlings for that given use of resources, and into inefficiency of scale, due essentially to an inadequate operational dimension. In practice, the indicators of efficiency were recalculated under the hypothesis of variable scale returns, according to the following model initially proposed by Charnes et al. (1978):

$$
\text { Eff }=\frac{\sum r u_{r} y_{r j}}{\sum i v_{i} x_{r j}},
$$

where $y_{r j}=$ the amount of the $r$ th output from nursery $j, u_{r}=$ the weight given to the $r$ th output, $x_{i j}=$ the amount of the $i$ th input used by nursery $j$, and $v_{i}=$ the weight given to the $i$ th input.

In particular, the final model applied to nurseries was the following output-oriented one:

$$
\begin{gathered}
\text { Eff }=\operatorname{Max} \sum r u_{r} y_{r j 0} \\
\sum r u_{r} y_{r j}-\sum i v_{i} x_{i j} \leq 0 ; \forall_{j} \\
\sum i v_{i} x_{i j 0}=1 \\
u_{r}, v_{i} \geq 0 ; \forall_{r}, \forall_{i} .
\end{gathered}
$$

Thus, the units that under the latter hypothesis, have obtained a higher score than those corresponding to the hypothesis of constant returns are precisely the nurseries whose inefficiency also depends on the factors of scale. To evaluate to what extent the results reflect an effective inability to organize the activity of the nurseries investigated rather than an inadequacy of the scale at which they operate, the efficiency results of the model with CRS are compared with those of a model of VRS. In the first case, as previously stated, the efficiency of a nursery is evaluated in relation to the behavior of all the other nurseries present in the sample, whereas in the second case, the comparison is made only with those nurseries that operate on the same scale: as a result, the efficiency results of the model with varying returns are not inferior to those of the model with constant returns to scale.

On completion of this investigation, the indicators of efficiency were used as a dependent variable in a Tobit regression model, proposed originally by James Tobin (1958) for describing the relationship existing between a variable-dependent observable $y_{i}$ - which cannot assume values lower than zero-and one or more variables. In particular, the dummy variable that selects nurseries distinguishes those cases for which the problems of efficiency are believed to be more severe according to the following model:

$$
\theta_{i}=\alpha+\mathrm{X}_{\mathrm{i}} \bar{\beta}+\varepsilon_{i}, \quad i=1,2, \ldots, N,
$$

where $\theta_{i}$ is the index of efficiency of the DEA for the $i$ th nursery, $\alpha$ is the estimated coefficient of interception, $\mathrm{X}_{i}$ is a matrix composed of as many vectors as the explicative variables of the model, $\beta$ is a vector of estimated coefficients, and $\varepsilon$ represents the stochastic error. The elaborations were carried out using STATA software, version 12, according to the models proposed by $\mathrm{Ji}$ and Lee (2010) and Tobit regression for STATA (StataCorp., 2017).

\section{Results}

Characteristics of the nurseries investigated. The empirical survey was concentrated in Sicily, a region that intercepts $8 \%$ of the total number of nurseries in Italy (ISTAT, 2015). This share increases in the case of nurseries of horticultural plants because of the specific nature of the pedoclimatic environment and to the significant horticultural vocation in the open field and under cover that is found on the island $(22 \%$ in surface area), which justifies the presence of structures supporting the construction of quality supply chains. Sicilian nursery production is therefore also directed toward export to other national and international areas (Timpanaro et al., 2013).

The territorial localization can be gauged from Fig. 1, from which one can note the polarization of structures in areas with strong horticultural vocations (Pachino for Syracuse, Vittoria for Ragusa, Marsala for Trapani, and the coastal strip for Catania and Messina). In these areas, tomato production has gained prestigious recognitions in quality and great market potential (Protected Geographical Indication from the EU and inclusion in the List of Traditional Agri-Food Products of DM 350/99). The general characteristics of the enterprises to be found are included in Table 1. The nurseries have an average spread of more than 4 ha and a used agricultural area of 2.34 ha divided on an average of more than 11 production units with protective facilities (greenhouses). The degree of technological development of these units can be deduced from the size of the investments in land and stock, averaging $\approx 530,000$ euros for the former and 390,000 euros for the latter. In terms of land investment, the greatest fluctuations between the minimum and maximum values are observed in the case of greenhouses (from 80,000 to 643,000 euros), attesting to the existence of a pronounced gap in the level of innovation used. Similar considerations can be made for the mechanical means used (ranging from almost 79,000 to 220,000 euros) and for other machinery, plant, and equipment used to support the production (sowing and germination room, fertigation systems, etc.).

The relationships between capital and land and between capital and labor represent important structural characteristics in analyzing the economic and efficiency results in the horticultural nurseries investigated (Khan et al., 2004). In particular, the results of the analysis in some cases demonstrate the apparent oversizing of plants and structures that are potentially capable of generating diseconomies of scale both internally (due to limited technical and directional adaptation) and externally (due to factors including the difficulty of accessing credit and the structural and infrastructural shortcomings of the territories in which the nurseries are located).

Economic results and production costs. The nurseries that were surveyed registered an average production of tomato seedlings of more than five million units altogether, taking account of the multitude of production cycles activated in 2016 (Table 2). The sample, moreover, presents a wide variation in production, with a minimum of 500,000 seedlings and a maximum of almost 14.4 million seedlings. The interest in the cultivation of the tomato dates back to the economic importance held by this solanacea in the horticultural economy both in the greenhouse and in the open field. The tomato in Sicily, in fact, accounts for more than 25.3\% (288 million euros) of the value of Italian tomato production (amounting to 1.1 billion euros according to ISTAT, 2015), and its cultivation is so widespread that it is always present in the product portfolios of all the nurseries present in the territory.

Considering an average unit revenue of 0.54 euros per seedling, this results in an average turnover of more than three million euros. The wide variation in turnover (from a minimum of 285,000 euros to a maximum of nearly 10.5 million euros), however, shows the existence of profound differentiations in productive levels in the relationship between the combinations of factors, in entrepreneurial abilities, and ultimately, in the level of efficiency in the different realities observed. The average overall costs totaled more than 1.55 million euros, ranging from a minimum of 179,000 euros to a maximum of 6.3 million euros. 


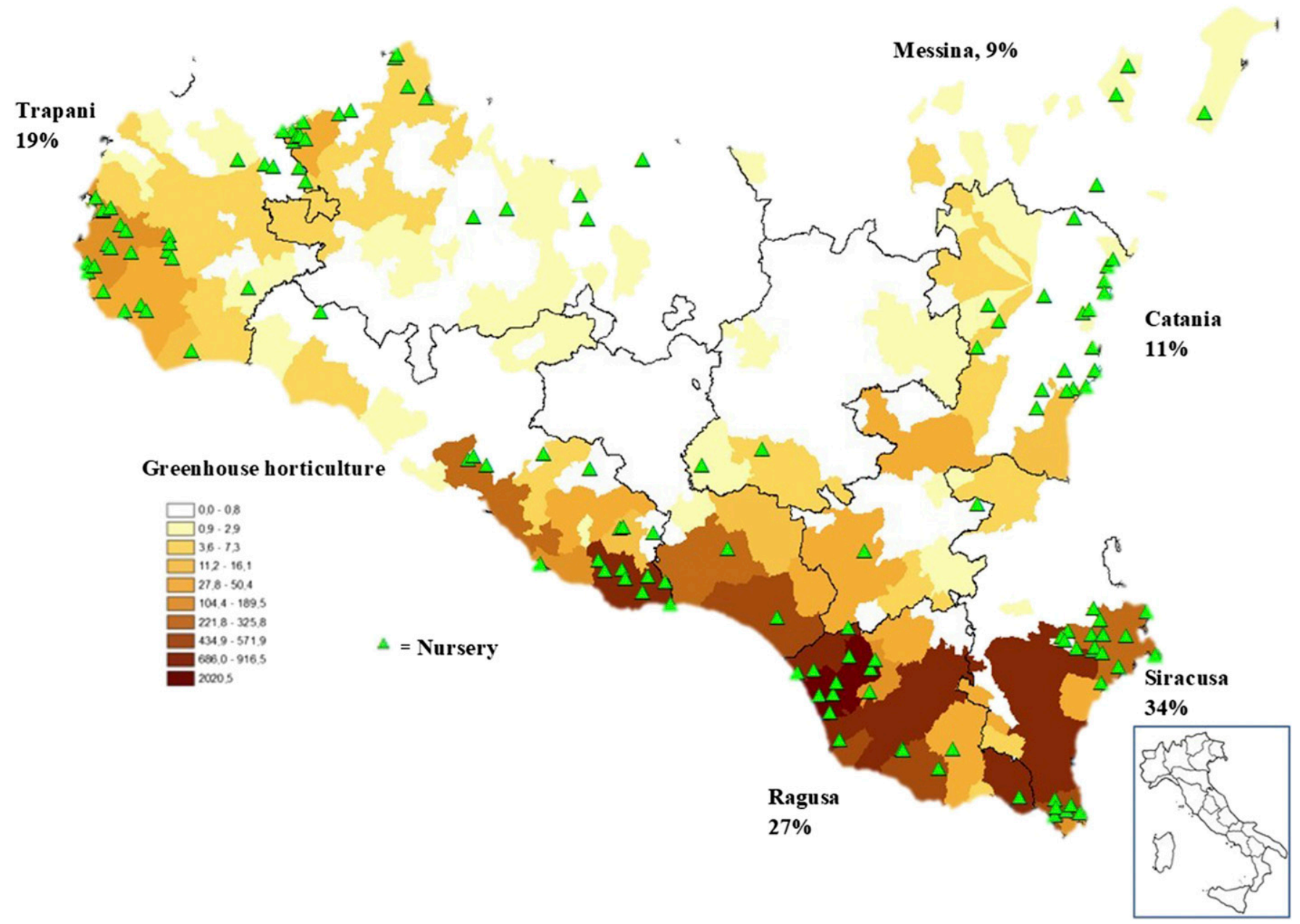

Fig. 1. Spatial distribution of farms in the sample in Sicily. The nurseries have been chosen in proportion to their territorial diffusion and to the localization of greenhouse horticulture. The colored areas indicate the spread of horticulture in the greenhouse, and the symbols the nurseries. In these areas, the tomato (Solarnum lycopersicum L.) production has gained prestigious recognitions in quality and great market potential.

Table 1. General characteristics of the nurseries that produce seedlings of tomato (2016).

\begin{tabular}{lrrrrr}
\hline Indication & \multicolumn{1}{c}{ Avg } & \multicolumn{1}{c}{ Minimum } & \multicolumn{1}{c}{ Maximum } & \multicolumn{1}{c}{ Median } & \multicolumn{1}{c}{ SD } \\
\hline Total width (ha) & 4.38 & 1.12 & 10.50 & 4.00 & 2.16 \\
Nursery area (ha) & 2.34 & 0.71 & 5.96 & 2.25 & 1.20 \\
Greenhouse, $n$ & 11.07 & 2.78 & 32.23 & 12.14 & 4.99 \\
Land investment (euro) & & & & & \\
$\quad$ Rural buildings & $212,193.61$ & $100,000.00$ & $328,385.00$ & $211,379.50$ & $53,148.97$ \\
$\quad$ Irrigation systems & $79,582.50$ & $50,000.00$ & $135,000.00$ & $76,072.00$ & $19,467.50$ \\
$\quad$ Greenhouse & $236,541.82$ & $80,000.00$ & $643,500.00$ & $186,712.50$ & $165,838.83$ \\
Tractors, motorcycles, and farm equipment (euro) & & & & \\
$\quad$ Seedling/germination machines & $173,571.98$ & $130,000.00$ & $195,000.00$ & $177,873.00$ & $14,210.76$ \\
$\quad$ Other mechanical means & $78,500.00$ & $78,500.00$ & $220,000.00$ & $146,018.50$ & $31,987.58$ \\
$\quad$ Irrigation pumps & $68,325.61$ & $37,500.00$ & $89,700.00$ & $70,593.50$ & $11,085.86$ \\
$\quad$ Other & $66,395.80$ & $15,500.00$ & $115,000.00$ & $68,484.00$ & $27,021.50$ \\
\hline
\end{tabular}

Source: elaboration on direct data collection.

In the scenario observed, a parallel differentiation exists in the value of the cost per seedling, even if the nursery entrepreneur is well aware of the necessity of increasing the number of units (seedlings) produced as much as possible to see decreases in the average cost of producing them. However, the possibilities for the expansion of production are subject to a multitude of constraints, stemming both from the rigidity of the productive structure (above all, owing to the substantial fixed capital and to the imperfect divisibility of a variety of productive factors) and from the competitive market in which they operate: a situation in which individual producers can have no influence over the prices of products and factors. Different types of consequences may occur:

- The enterprise expands to such a degree as to no longer be able to operate efficiently because it does not enjoy constant returns to scale for all output levels, and therefore, the problems of coordination that arise can cause it to enter a phase of diminishing returns.
- The enterprise expands to such a degree as to totally dominate the market for the product, depressing the competition to the point of exploiting its own size to influence the market price (this is frequently the case where the nursery holds the breeding rights to species and varieties). In other words, the enterprise would have no motive for adhering to the model of competitive maximization of profit.

- The enterprise can realize a positive profit with a technology offering constant returns to scale in the same way that other enterprises can; in this case, if all the nurseries increase their respective production, it follows that the profit for all the nurseries will be reduced. In fact, Fig. 2 shows the relative weight of the various items of average cost in the production of tomato seedlings in large part owing to the reintegration of factors external to the enterprise (75\% materials and $20 \%$ stocks and other attributes).

Naturally, a technology can be characterized by different returns to scale corresponding to different levels of production; however, in general, the individual nursery should try to operate at an optimal scale: not too small if the 
Table 2. Descriptive statistics of inputs and outputs (2016).

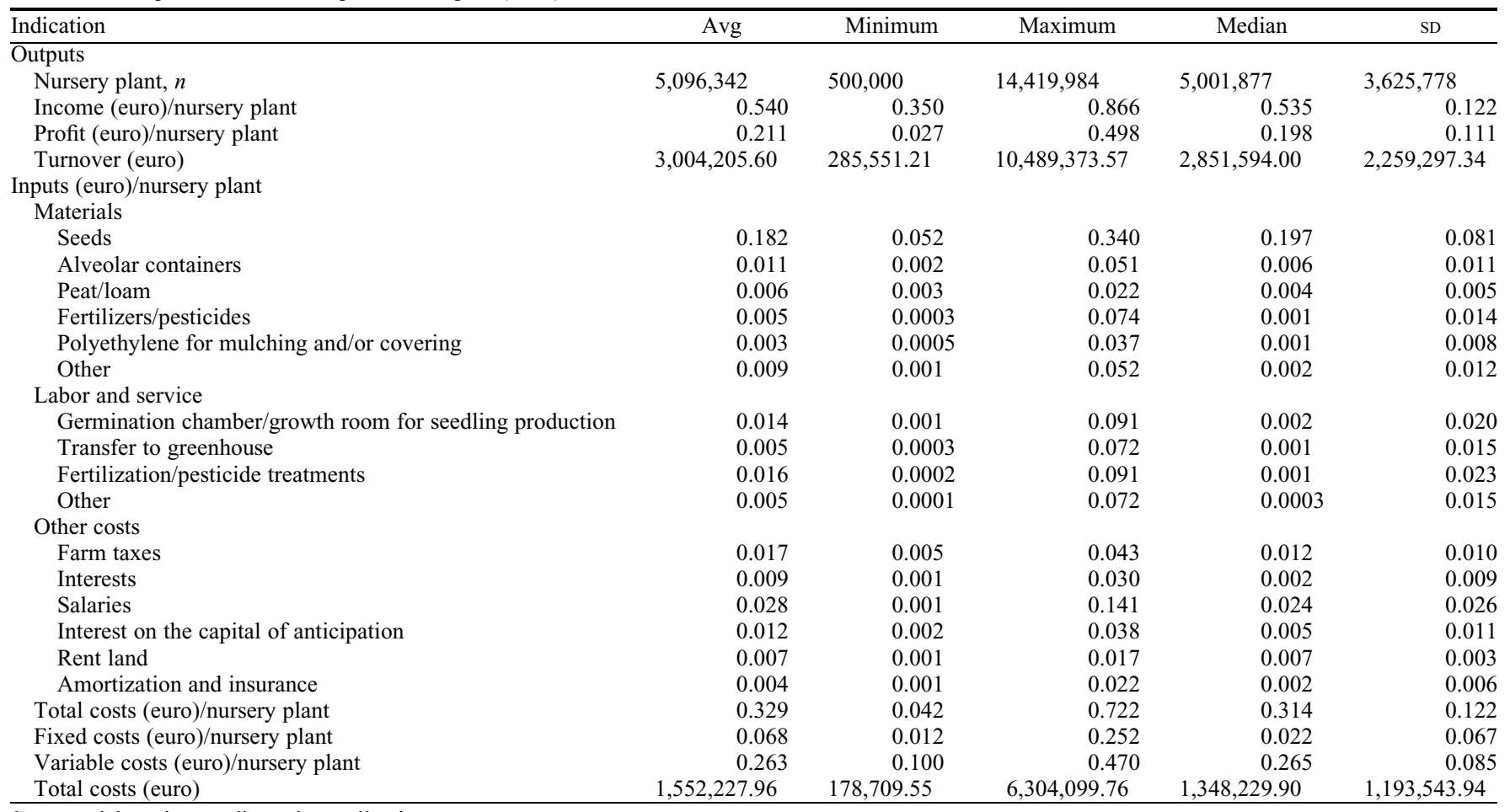

Source: elaboration on direct data collection.

returns to scale are increasing, not too large if, on the other hand, they are decreasing (Timpanaro et al., 2013).

Achieving the optimum scale is not easy, and the following question for the nursery remains: how should a nursery behave when it is obliged to allocate a given level of production among multiple productive processes in such a way as to minimize the overall cost of production? In this case, the literature amply shows that the problem of the maximization of profit can be decomposed in two phases: the minimization of the costs necessary to produce a quantity $y$ of output and the determination of the quantity of output that corresponds to the maximization of profit. Therefore, the problem for the nursery simply becomes that of having the appropriate instruments or preparations to be able to evaluate the TE (with the best use of technology) and economic efficiency (with the best use of technology and producing at a minimum cost) of these processes in such a way as to calibrate their activity (Scuderi et al., 2015, 2016).

Results of the analysis of efficiency with the DEA method. DEA was conducted using an output-oriented approach because the intention was to evaluate the maximization of turnover for every individual nursery. Therefore, having obtained the TE scores of the units, representative of their capacity to produce a determined quantity of output from a determined set of inputs, a breakdown of the measure of efficiency was then realized in its three components: overall, purely technical, and scale.

The scores of TE resulting from the application of the model are shown in Table 3 . The median-estimated TE (VRS measure)

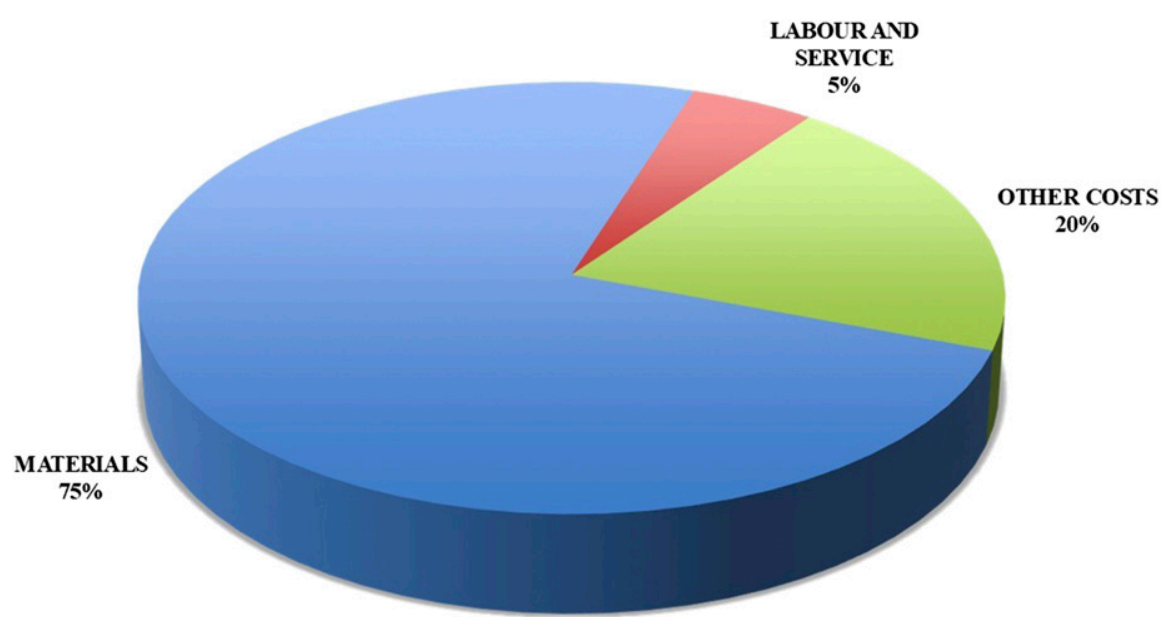

Fig. 2. Structure of the average production cost of tomato seedlings in nurseries detected in Italy (2016) Production costs were calculated by dividing them into three large categories, such as "materials" (seeds; containers; water; fertilizers; pesticides; and others), "labor and services" (farm works and mechanized services; mediation; transport; professional consulting; and others), and "other costs" (quotas on land investments; quotas on stock investments; family and other labor costs; farm taxes and wages and social security charges; own capital cost; own land cost; and others).

and efficiency of scale are 0.857 and 0.919 , respectively. By imposing nonincreasing scale returns (NIRS), we discovered that most of the enterprises have an increasing return to scale. This finding implies that the inefficiency of scale is mainly due to enterprises that operate under a nonoptimal scale, in other words, enterprises in which output is below optimal levels and should be increased to reach the optimum scale. There are 22 nurseries in the sample (44\%) that are technically efficient. In the context of the frontier of best practices, 21 of the most efficient firms registered variable returns to scale and seven registered diminishing returns to scale. In the nurseries operating on a suboptimal scale (14\%), the efficiency to scale is noticeably lower than that estimated for the enterprises operating on a supraoptimal scale (1.112).

The arithmetic average and the median are the same for TE but different for scale efficiency (SE). The median of the SE is slightly greater than the average because the distribution is inclined to the left with fewer enterprises at levels below the SE.

The limited standard deviations show that the values of efficiency in the data set are 
close to the median and the efficiency is relatively more heterogeneous than the efficiency of scale.

In fact, Table 4 and Fig. 3 both show that technical inefficiency is the principal source of overall inefficiency rather than inefficiency of scale. In total, $16 \%$ of the nurseries investigated have a TE score of less than 0.7 , against an efficiency scale score of $8 \%$, whereas the overall sample in the class score $0.7-0.8$ is equal to $20 \%$ for TE and $10 \%$ for SE.

The analysis reveals that, on average, the nurseries should be able to increase the production of tomato seedlings by $\approx 15 \%$ by using their resources more rationally $(\mathrm{TE}=$ 0.857 ) rather than operating on an inefficient scale.

Analysis of the cause factors of inefficiency in the nurseries. To explain the variations in TE and SE among the nurseries studied, the efficiency scores were subjected to a Tobit regression model considering the characteristics of the productive structures and the principal

Table 3. Estimated technical efficiency (TE) and scale efficiency (SE) for data envelopment analysis model (2016).

\begin{tabular}{|c|c|c|c|c|}
\hline \multirow[b]{2}{*}{ Indication } & \multicolumn{4}{|c|}{ Efficiency } \\
\hline & $\mathrm{TE}^{\mathrm{CRS}}$ & $\mathrm{TE}^{\mathrm{VRS}}$ & $\mathrm{TE}^{\mathrm{NIRS}}$ & SE \\
\hline Mean & 0.7830779 & 0.8566543 & 0.9215603 & 0.9193968 \\
\hline SD & 0.1471978 & 0.1410231 & 0.1282919 & 0.1144524 \\
\hline Min & 0.5696780 & 0.5919310 & 0.5886590 & 0.5976860 \\
\hline $\operatorname{Max}$ & 1.0000000 & 1.0000000 & 1.0000000 & 1.0000000 \\
\hline Median & 0.781431 & 0.867623 & 0.999999 & 0.980330 \\
\hline Eff DMU, $n$ & 10 & 17 & 23 & 50 \\
\hline \multicolumn{5}{|l|}{ Nature of returns } \\
\hline MPSS, firms $n$ & & & & 22 \\
\hline drs, firms $n$ & & & & 7 \\
\hline \multirow[t]{3}{*}{ irs, firms $n$} & & & & 21 \\
\hline & \multicolumn{4}{|c|}{ Returns to scale } \\
\hline & Percentage of farms & & SE & \\
\hline Supraoptimal scale & 42.0 & & 0.87813 & \\
\hline Optimal scale & 44.0 & & 1.000000 & \\
\hline Suboptimal scale & 14.0 & & 0.78986 & \\
\hline Total sample & 100.0 & & 0.91940 & \\
\hline
\end{tabular}

Source: elaboration on direct data collection.

$\mathrm{CRS}=$ constant return scale; drs = diminishing returns to scale; irs = increasing scale returns; NIRS = nonincreasing scale returns; VRS = variable return scale; Eff DMU = efficient decision making unit; MPSS $=$ most productive scale size.

Table 4. Frequency distribution of technical and scale efficiencies from the DEA ${ }^{\text {VRS }}$ model (2016).

\begin{tabular}{|c|c|c|}
\hline \multirow[b]{2}{*}{ Efficiency score } & \multicolumn{2}{|c|}{ Technical efficiency } \\
\hline & Number of farms in range & Percentage \\
\hline$<0.500$ & - & - \\
\hline $0.501-0.600$ & 5 & 10.0 \\
\hline $0.601-0.700$ & 3 & 6.0 \\
\hline $0.701-0.800$ & 10 & 20.0 \\
\hline $0.801-0.900$ & 9 & 18.0 \\
\hline $0.901-0.999$ & 6 & 12.0 \\
\hline 1.000 & 17 & 34.0 \\
\hline \multirow[t]{2}{*}{ Total } & 50 & 100.0 \\
\hline & Sca & Percentage \\
\hline$<0.500$ & - & - \\
\hline $0.501-0.600$ & 1 & 2.0 \\
\hline $0.601-0.700$ & 3 & 6.0 \\
\hline $0.701-0.800$ & 5 & 10.0 \\
\hline $0.801-0.900$ & 4 & 8.0 \\
\hline $0.901-0.999$ & 15 & 30.0 \\
\hline 1.000 & 22 & 44.0 \\
\hline Total & 50 & 100.0 \\
\hline
\end{tabular}

Source: elaboration on direct data collection.

$\mathrm{DEA}=$ data envelopment analysis; VRS $=$ variable return scale. of organizational diseconomy due to the fragmentation of the process, difficulties of coordination, and management of the operations of cultivation), as shown by a coefficient of $-24,055.3$ and an intercept of $-24,054.1641$; the employment of labor and services (often tied to scarce specialization of labor, limited professionalism, and the difficulty of obtaining services to support production on the local market), with a coefficient of -11.7045 and an intercept of -10.5686 ; the materials used (especially in regard to certified seed, often tied to hybrid species and varieties developed by international seed and genetic firms, with aggravations linked to high royalties, and often with levels of germination that do not correspond to those declared with an increased level of failures), with a coefficient of -2.7845 and an intercept of -1.6486 ; and by investments of stock (with a coefficient and intercept, respectively, of -1.431 and -0.295 ) and land (coefficient of -0.520 and intercept of 0.616 ).

To evaluate the validity of the chosen model and the initial assumptions, the normal distribution of residues, the independence of residues from the values of the independent variable, and the homogeneity of the variances of residues, we elaborated Fig. 4, which shows that the model adapts well to the interpretation for a good part of the nurseries investigated.

Thus, it can be said that the enterprises in the lead, in respect to higher values of profit, are characterized by lower production costs, by business strategies that favor investment (renovation of structures and plant to increase the productive potential), by a more efficient use of specialized manpower, and by the realization of a process and a product of quality, demanded by horticultural entrepreneurs downstream from the nursery activity.

\section{Concluding Considerations}

The results of the research have demonstrated the importance played by the choice of process in the production of tomato seedlings and, in particular, by the definition of the level of use of variable inputs (materials, labor, and services), and by the intensity of the investment in certain fixed factors (greenhouses especially), and different capital goods, in terms of their reflection on production costs.

In addition, it should be noted that there is a strong differentiation in regard to the economic dimension of the nurseries investigated, indicated by an inverse correlation between investments in productive structures and productive potential expressed by turnover, calling into question the choices that determine the allocation of resources within or outside the tomato seedling productive process (Hall, 2004; Lewis et al., 2014). Public support for investments sometimes leads to oversizing production units and helps increasing the weight of imperfect factor divisibility.

In the efficient nurseries, it is noticeable that the remuneration of capital and labor 


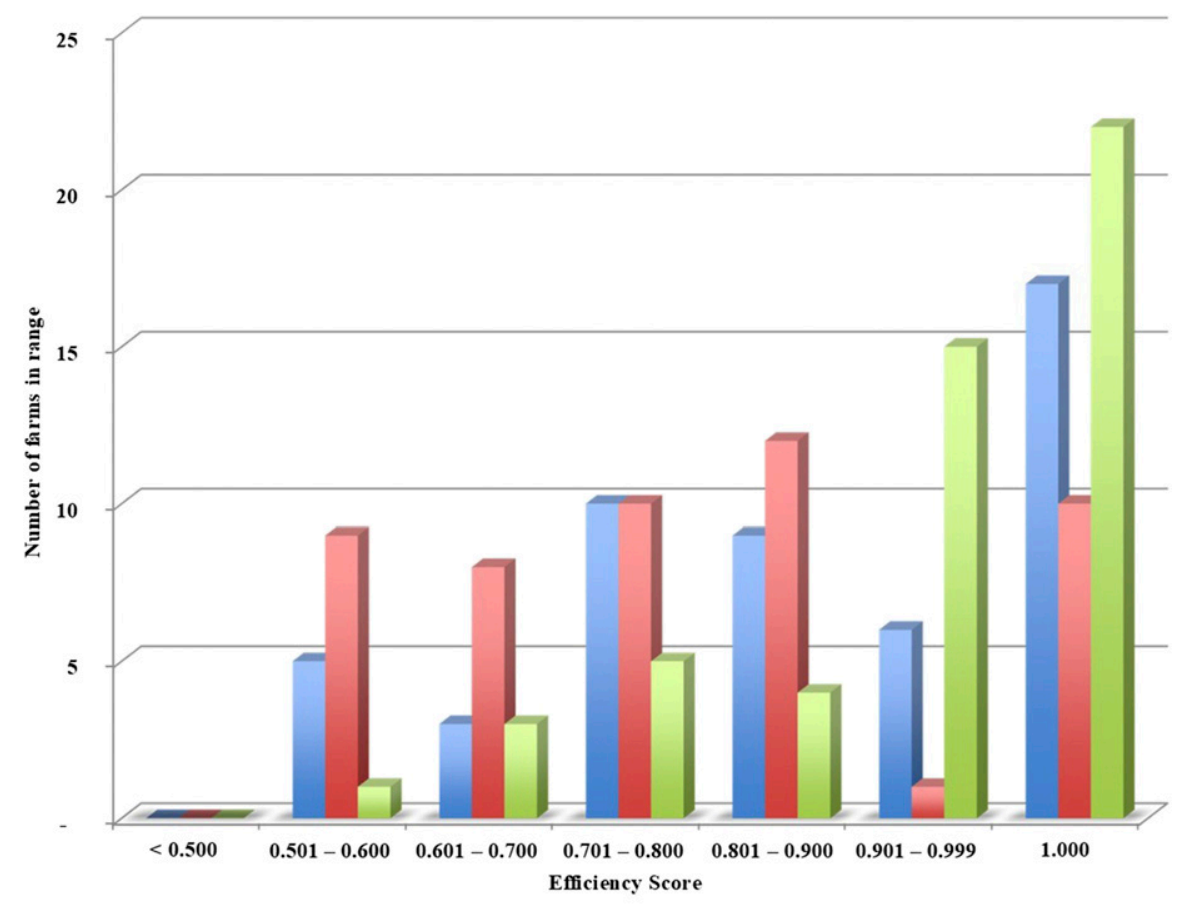

$\equiv$ Technical efficiency (VRS) $\quad=$ Technical efficiency (CRS) $\quad$ Scale efficiency

Fig. 3. Efficiency distributions for efficiency scores in tomato nurseries. Technical inefficiency is the principal source of overall inefficiency, rather than inefficiency of scale $(16 \%$ of the nurseries have a technical efficiency score of under 0.7 ).

Table 5. Results of Tobit regression on detected nurseries (2016).

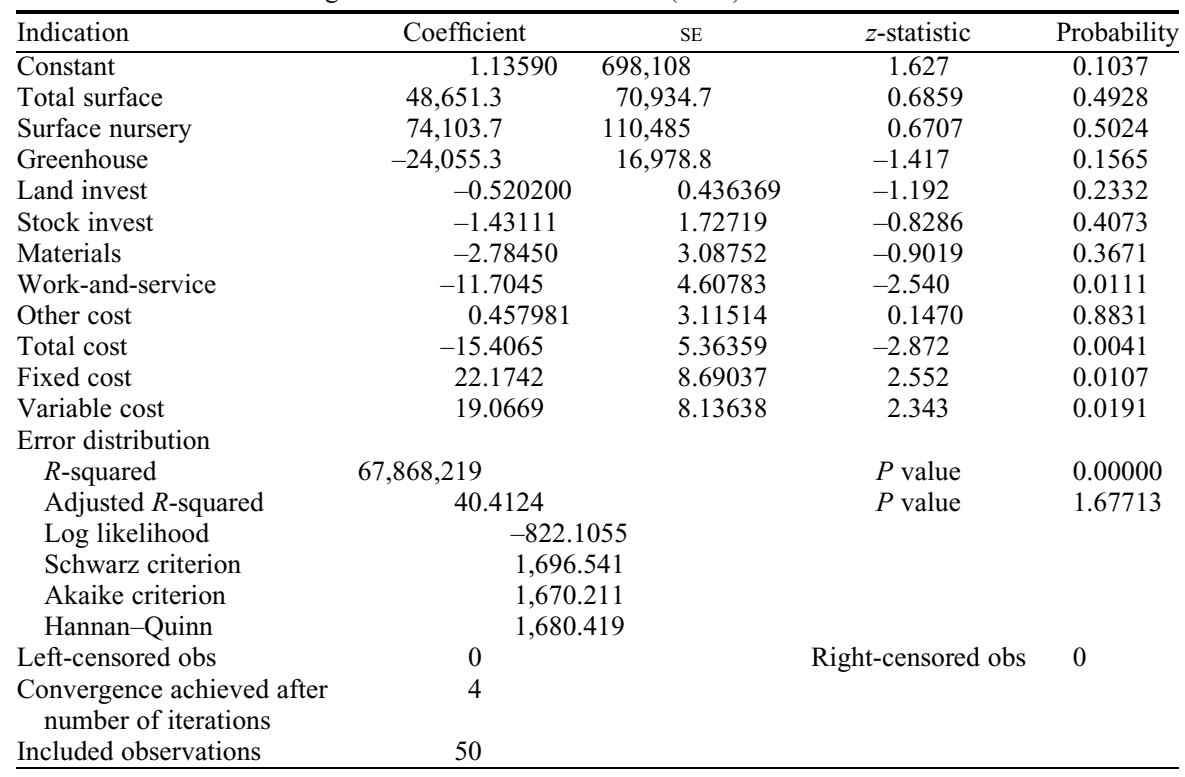

Source: elaboration on direct data collection.

factors simultaneously affects both the economies of SE and the allocative efficiency, deriving from the prices of purchasing productive means and services and from the sales of the seedlings, and the productive and marketing strategies aimed at increasing business revenue. In the first case, this materializes, above all, through the diversification of the productive systems and the offering of seedlings of several species and varieties
In conclusion, we do not have to overlook the considerable evolution of the sector, with the generational turnover of enterprises and the emergence of new productive realities market oriented, and are potentially more interested in nursery products (Hodges and Haydu, 2000). In the future, a possible increase in demand for seedlings is expected under the pressure of a growing demand for "ready-to-use" propagation materials (seedlings ready for the next transplant) - frequently demanded by intensive horticulture - or the marked heterogeneity of human capital who manage and work in the nurseries. This is closely related to motivational, cultural, and managerial aspects in terms of their relative importance in determining the degree of business efficiency. The considered realities still manifest perceptible margins for improvement, given that the degree of estimated efficiency varies within a very wide range. This is an improvement that can be supported by adequate research policies, experimentation, and the sharing of results. The nursery, as an elected center of innovation, must be the promoter of new paths of integration of the supply chain, upstream with activities of genetic improvement (with the diffusion of new species and varieties characterized by certified and reliable levels of germination) and downstream with producers and consumers (also with the creation of multichannel communication aimed at promoting quality and the traceability of the supply chain).

Therefore, nurseries must be driven by the challenge of increasingly globalized markets, with innovative products and process technologies that can simplify the production process (from breeding to new varieties, etc.), reduce the costs of production, and increase the quality, reliability, rapidity and sustainability of production processes. This evolutionary path is heavily dependent on the economic size of the enterprise and the linkage of the nursery to the market. Upstream, it is necessary to encourage the use of extraregional contexts for the supply of propagating material (seeds); downstream, it is necessary to promote business policies that can overcome the limits of the reference to an exclusively local market (Uva, 2000). In the latter case, all those innovations that can change the nature of the production processes will have a central role. In fact, the finished products (e.g., 30- or 40-d seedlings) that are hardly liable to face long journeys without physiological stress provide objective limits on marketing to extraregional markets (Behe et al., 2008; Brumfield, 2010).

Without overlooking the problems related to the sample size and its geographical diffusion, from this perspective, it is considered necessary to maintain constant monitoring of the performance of the sector to collect further information to develop interventions that are aimed at supporting the operators by comparisons with other areas-national and international-with strong horticultural vocations. 


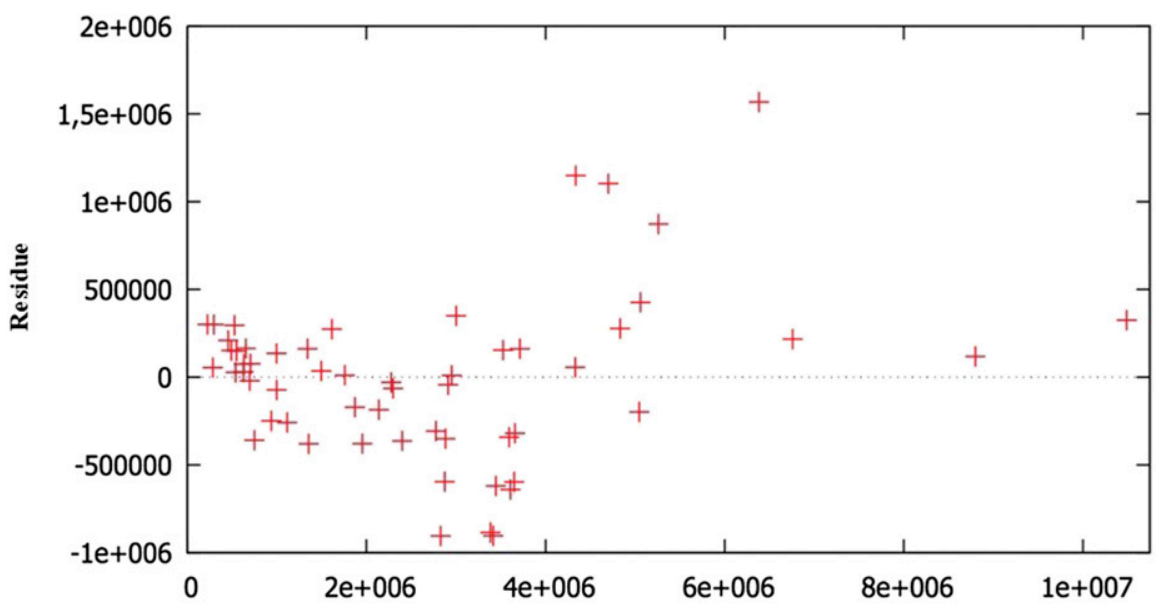

TurnoverEUR

Fig. 4. Residues of regression (=Turnover in euros observed - estimated). The model adapts to the interpretation for a good part of the nurseries investigated. The enterprises in the lead are characterized by lower production costs, by business strategies that favor investment, by a more efficient use of specialized manpower, and by the realization of a process and a product of quality, demanded by horticultural entrepreneurs downstream from the nursery activity. They show higher values of profit.

\section{Literature Cited}

Aparicio, J., F. Borras, J.T. Pastor, and F. Vidal. 2013. Accounting for slacks to measure and decompose revenue efficiency in the Spanish Designation of Origin wines with DEA. Eur. J. Oper. Res. 231(2):443-451.

Aramyan, L., C.J. Ondersteijn, O. Van Kooten, and A.O. Lansink. 2006. Performance indicators in agri-food production chains, p. 49-66. In: Quantifying the agri-food supply chain. Springer, Dordrecht, The Netherlands.

Banker, R.D., A. Charnes, and W.W. Cooper. 1984. Some models for estimating technical and scale inefficiencies in data envelopment analysis. Mgt. Sci. 30(9):1078-1092.

Basile, F., V.T. Foti, and G. Timpanaro. 2002. Comparative economic analyses between conventional and eco-compatible cactus pear cultivation in Italy. Acta Hort. 581:47-61.

Battese, G.E. 1992. Frontier production functions and technical efficiency: A survey of empirical applications in agricultural economics. Agr. Econ. 7(3-4):185-208.

Behe, B.K., J.H. Dennis, C.R. Hall, A.W. Hodges, and R.G. Brumfield. 2008. Regional marketing practices in US nursery production. HortScience 43:2070-2075.

Bonfiglio, A. 2006. Efficiency and productivity changes of the Italian agrifood cooperatives: A Malmquist index analysis. Università Politecnica Delle Marche, Quaderno di Ricerca.

Brumfield, R.G. 2010. Strategies producers in the northeastern United States are using to reduce costs and increase profits in tough economic times. HortTechnology 20:836-843.

Charnes, A., W.W. Cooper, and E. Rhodes. 1978. Measuring the efficiency of decision making units. Eur. J. Oper. Res. 2(6):429-444.

Coelli, T. 1995. Recent developments in frontier modelling and efficiency measurement. Austral. J. Agr. Econ. 39(3):219-245.

Dadura, A.M. and T.R. Lee. 2011. Measuring the innovation ability of Taiwan's food industry using DEA. Innovation: The European Journal of Social Science Research 24(1-2):151172.

European Commission. 2010. Developments in the income situation of the EU agricultural sector.
Kuosmanen, T. 2006. Stochastic nonparametric envelopment of data: Combining virtues of SFA and DEA in a unified framework. Keskustelualoitteita 46:1-29.

Latruffe, L. 2010. Competitiveness, productivity and efficiency in the agricultural and agri-food sectors. OECD Food, Agriculture and Fisheries Papers, No. 30. OECD Publishing, Paris, France.

Lewis, M., C. Kubota, R. Tronstad, and Y.J. Son. 2014. Scenario-based cost analysis for vegetable grafting nurseries of different technologies and sizes. HortScience 49:917-930.

Liu, J.S., L.Y.Y. Lu, W-M. Lu, and B.J.Y. Lin. 2013. A survey of DEA applications. Omega 41 (5):893-902.

Liu, H.Y. and K. Lv. 2010. Productive efficiency and its influencing factors of winemaking firms in China: A research based on DEA-Tobit approach. Collected Essays Finance Econ. 2 (1):1-6.

Madau, F.A. 2015. Technical and scale efficiency in the Italian citrus farming: A comparison between SFA and DEA approaches. Agr. Econ. Rev. 16(2):15-27.

Martínez-Carrión, J.M. and F.J. Medina. 2010. Change and development in the Spanish wine sector, 1950-2009. J. Wine Res. 21 (1):77-95.

Mutonyi, S. and A. Gyau. 2014. Measuring performance of small and medium scale agrifood firms in developing countries: Gap between theory and practice. In: 140th Seminar, Perugia, Italy, 13-15 Dec. 2013 (No. 163339). European Assn. Agr. Econ.

Pagotto, M. and A. Halog. 2016. Towards a circular economy in Australian agri-food industry: An application of input-output oriented approaches for analyzing resource efficiency and competitiveness potential. J. Ind. Ecol. 20:1176-1186.

Power, K.C., J.B. Fitzgerald, G.E. Meyer, and D.D. Schulte. 1991. Plant production costaccounting/management system. HortScience 26:201-203.

Rivard, C.L., O. Sydorovych, S. O'Connell, M.M Peet, and F.J. Louws. 2010. An economic analysis of two grafted tomato transplant production systems in the United States. HortTechnology 20:794-803.

Scuderi, A., L. Sturiale, and G. Timpanaro. 2015. The importance of "origin" for on line agrifood products. Quality Access Success 16:260 266.

Scuderi, A., V.T. Foti, G. Timpanaro, and L. Sturiale. 2016. Economic and environmental analysis of organic early potatoes. Acta Hort. 1142:193-200.

Sellers-Rubio, R., V. Alampi Sottini, and S. Menghini. 2016. Productivity growth in the winery sector: Evidence from Italy and Spain. Intl. J. Wine Bus. Res. 28(1):59-75.

Sharma, K.R., P.S. Leung, and H.M. Zaleski. 1997. Productive efficiency of the swine industry in Hawaii: Stochastic frontier vs. data envelopment analysis. J. Productivity Anal. 8:447-459.

Sharma, K.R., P.S. Leung, and H.M. Zaleski. 1999. Technical, allocative and economic efficiencies in swine production in Hawaii: A comparison of parametric and nonparametric approaches. Agr. Econ. 20:23-35.

Sipiläinen, T. and A. Oude Lansink. 2005. Learning in organic farming-An application on Finnish dairy farms. In: XI Congr. EAAE, Copenhagen, Denmark.

StataCorp. 2017. Stata Statistical Software: Release 15. StataCorp LLC, College Station, TX. 
Timpanaro, G., A. Urso, C. Prato, and V.T. Foti. 2015. Evaluating the potential for development of vegetable nursery industry: Analysis in an important vegetable region in Italy. Amer. J. Agr. Biol. Sci. 10(2):74-82.

Timpanaro, G., V.T. Foti, and D. Spampinato. 2013. Organic farming in Sicily: Analysis and perspectives through the main productive chains. Quality Access to Success 14: 157-164.
Urso, A. 2014. L'utilizzo dei dati microeconomici della rete FADN-RICA per la valutazione delle politiche agricole: Ipotesi di sviluppo di un modello di analisi degli effetti dell'OCM vino sull'efficienza delle aziende vitivinicole italiane. Univ. Catania, PhD Diss. < archivia.unict. it>.

Urso, A., G. Timpanaro, F. Caracciolo, and L. Cembalo. 2015. Efficiency analysis of Italy's wine producers. Proc. 9th Intl. European Forum
Syst. Dyn. Innov. Food Netw. (144th EAAE Seminar), Igls, Austria.

Uva, W.F. 2000. An analysis of the economic dimensions of the greenhouse industry in New York, United States. Acta Hort. 536: 397-403.

Voulgaris, F. and C. Lemonakis. 2013. Productivity and efficiency in the agri-food production industry: The case of fisheries in Greece. Procedia Technol. 8:503-507. 